\title{
Erratum to: The Effect of Ti on Mechanical Properties of Extruded In-Situ Al-15 pct $\mathrm{Mg}_{2} \mathrm{Si}$ Composite
}

NILOOFAR SOLTANI, AMIN BAHRAMI, and MARTIN IGNACIO PECH-CANUL

DOI: $10.1007 / \mathrm{s} 11661-013-1909-2$

(C) The Minerals, Metals \& Materials Society and ASM International 2013

Erratum to: METALLURGICAL AND MATERIALS

TRANSACTIONS A, Vol. 44, No. 9,

pp. $4366-4373$

DOI 10.1007/s11661-013-1747-2

AN Acknowledgment is added to the original article as follows:

Several of the micrographs were taken during Amin Bahrami's stay at the University of Tehran.

NILOOFAR SOLTANI, Ph.D. Student, is with the Department of Materials Science and Engineering, Sharif University of Technology, Tehran, Iran, also with the Centro de Investigación y de Estudios Avanzados del IPN Unidad Saltillo, Av. Industria Metalúrgica No. 1062, Parque Industrial, 25900, Ramos Arizpe, COAH, Mexico. AMIN BAHRAMI, Ph.D. Student, is with the Imam Khomeini International University, Qazvin, Iran, also with the Centro de Investigación y de Estudios Avanzados del IPN Unidad Saltillo. Contact e-mail: amin. bahrami@cinvestav.edu.mx MARTIN IGNACIO PECH-CANUL, Professor, is with the Centro de Investigación y de Estudios Avanzados del IPN Unidad Saltillo.

The online version of the original article can be found under doi:10.1007/s11661-013-1747-2.

Article published online July 27, 2013 